\title{
High anti-SARS-CoV-2 antibody seroconversion rates before the second wave in Manaus, Brazil, and the protective effect of social behavior measures: Results from the DETECTCoV-19 cohort.
}

Pritesh Lalwani ( $\sim$ pritesh.lalwani@fiocruz.br)

Instituto Leônidas \& Maria Deane (ILMD/Fiocruz Amazônia) https://orcid.org/0000-0003-2996-0446

Roger Araujo-Castillo

Facultad de Ciencias de la Salud, Universidad Peruana de Ciencias Aplicadas

Christian Ganoza

Instituto de Medicina Tropical Alexander von Humboldt, Universidad Peruana Cayetano Heredia

Barbara Salgado

Instituto Leônidas e Maria Deane (ILMD), Fiocruz Amazônia

Ivanildo Pereira Filho

Instituto Leônidas e Maria Deane (ILMD), Fiocruz Amazônia

Danielle Silva

Instituto Leônidas e Maria Deane (ILMD), Fiocruz Amazônia

Thiago Morais

Instituto Leônidas e Maria Deane (ILMD), Fiocruz Amazônia

Maele Jordão

Instituto Leônidas e Maria Deane (ILMD), Fiocruz Amazônia

Jessica Ortiz

Instituto Leônidas e Maria Deane (ILMD), Fiocruz Amazônia

Aguyda Barbosa

Instituto Leônidas e Maria Deane (ILMD), Fiocruz Amazônia

Wlademir Salgado Sobrinho

Instituto Leônidas e Maria Deane (ILMD), Fiocruz Amazônia

Isabelle Cordeiro

Instituto de Ciências Biológicas (ICB), Universidade Federal do Amazonas (UFAM)

Júlio Souza Neto

Centro de Apoio Multidisciplinar (CAM), Universidade Federal do Amazonas (UFAM

Enedina Assunção

Centro de Apoio Multidisciplinar (CAM), Universidade Federal do Amazonas (UFAM

Cristiano da Costa

FVS-AM 


\section{Pedro Souza}

Programa de Pós - Graduação em Cirurgia, Faculdade de Medicina, Universidade Federal do Amazona (UFAM)

\section{Bernardino Albuquerque}

Faculdade de Medicina (FM), Universidade Federal do Amazonas (UFAM)

\section{Spartaco Astofi-Filho}

Instituto de Ciências Biológicas (ICB), Universidade Federal do Amazonas (UFAM)

Jaila Lalwani

Faculdade de Ciências Farmacêuticas (FCF), Universidade Federal do Amazonas (UFAM)

\section{Brief Communication}

Keywords: Seroconversion, SARS-CoV-2, Amazon, risk factors, incidence

Posted Date: March 22nd, 2021

DOI: https://doi.org/10.21203/rs.3.rs-351589/v1

License: (c) (1) This work is licensed under a Creative Commons Attribution 4.0 International License.

Read Full License

Version of Record: A version of this preprint was published at The Lancet Global Health on November 1st, 2021. See the published version at https://doi.org/10.1016/S2214-109X(21)00355-7. 
High anti-SARS-CoV-2 antibody seroconversion rates before the second wave in Manaus, Brazil, and the protective effect of social behavior measures: Results from the DETECTCoV-19 cohort.

Pritesh Lalwani ${ }^{1 \#}$, Roger V. Araujo-Castillo ${ }^{2^{*}}$, Christian A. Ganoza ${ }^{3^{*}}$, Bárbara Batista Salgado ${ }^{1 \S}$, Ivanildo Vieira Pereira Filho ${ }^{1,4 \S}$, Danielle Severino Sena da Silva ${ }^{1 \S}$, Thiago Barros do Nascimento de Morais ${ }^{1 \S}$, Maele Ferreira Jordão ${ }^{1 \S}$, Jessica Vanina Ortiz ${ }^{1 \S}$, Aguyda Rayany Cavalcante Barbosa ${ }^{1}, 5 \S$, Wlademir Braga Salgado Sobrinho', Isabelle Bezerra Cordeiro ${ }^{5}$, Júlio Nino de Souza Neto ${ }^{6}$, Enedina Nogueira de Assunção, Cristiano Fernandes da Costa ${ }^{7}$, Pedro Elias de Souza ${ }^{8}$, Bernardino Claudio de Albuquerque $^{9}$, Spartaco Astofi-Filho ${ }^{5,6^{*}}$, The DETECTCoV-19 study team and Jaila Dias Borges Lalwani ${ }^{4 \#}$.

${ }^{1}$ Instituto Leônidas e Maria Deane (ILMD), Fiocruz Amazônia, Manaus, Amazonas, Brazil

${ }^{2}$ Facultad de Ciencias de la Salud, Universidad Peruana de Ciencias Aplicadas, Lima, Peru

${ }^{3}$ Instituto de Medicina Tropical Alexander von Humboldt, Universidad Peruana Cayetano Heredia, Lima, Peru

${ }^{4}$ Faculdade de Ciências Farmacêuticas (FCF), Universidade Federal do Amazonas (UFAM), Manaus, Amazonas, Brazil

${ }^{5}$ Instituto de Ciências Biológicas (ICB), Universidade Federal do Amazonas (UFAM), Manaus, Amazonas, Brazil

${ }^{6}$ Centro de Apoio Multidisciplinar (CAM), Universidade Federal do Amazonas (UFAM), Manaus, Amazonas, Brazil 
${ }^{7}$ Fundação de Vigilância em Saúde do Amazonas (FVS/AM), Manaus, Amazonas, Brazil

${ }^{8}$ Programa de Pós - Graduação em Cirurgia, Faculdade de Medicina, Universidade Federal do Amazona (UFAM), Manaus, Amazonas, Brazil

${ }^{9}$ Faculdade de Medicina (FM), Universidade Federal do Amazonas (UFAM), Manaus, Amazonas, Brazil

\#Authors contributed equally

${ }^{*}$ Authors contributed equally

§Authors contributed equally

Key words: Seroconversion, SARS-CoV-2, Amazon, risk factors, incidence Running Title: Seroconversion and COVID-19 associated risk factors in Manaus

\section{Corresponding author}

Pritesh Lalwani, Dr. rer. nat.

Instituto Leônidas e Maria Deane (ILMD), Fiocruz Amazônia

Rua Terezina 476, Adrianópolis. Manaus - AM. CEP: 69057-070.

E-mail: pritesh.lalwani@fiocruz.br

Jaila Dias Borges Lalwani, PhD

Faculdade de Ciências Farmacêuticas (FCF), Universidade Federal do Amazonas (UFAM), Av. General Rodrigo Octavio Jordão Ramos, 1200 - Coroado I, Manaus AM, 69067-005

E-mail: jaila@ufam.edu.br 
The DETECTCoV-19 study team (alphabetical order)

Aldina lacy Paulain Holanda, Ana Lúcia Silva Gomes , Ana Paula Souza de França, André Victor Rabelo Monteiro, Andressa dos Passos Santos, Antônia de Sousa Teixeira, Antônio Vinicius Soares de Souza, Beatriz Pinheiro, Bianca Pires dos Santos, Brenda Pereira Farias, Bruno Nicolau Paulino, Caio Lúcio Andreola da Silva, Cinthya lamile Frithz Brandão de Oliveira, Dalila de Alcântara Martins, Eline Araújo de Oliveira, Elisson Denny da Costa Carvalho, Evillyn Fernandes Da Costa, Fernanda Rodrigues Fonseca, Fernanda Guilhon Simplicio, Fernanda Serrão Pereira, Gabriele Pimentel Sinimbu, Genilton de Oliveira Cardenes, Giane Alves da Silva, lago Sampaio Fernandes da Costa, Ingrid Silva Correia, Ilia Gilmara Carvalho dos Santos, Jackeline Vieira Guimarães, Juliana Correa Romana, Josineide de Oliveira Novo França, Kerollen Runa Pinto, Maria Fiamma Farias Freitas, Marne Carvalho de Vasconcellos, Marizete Candido Moraes, Matheus da Silva Damasceno, Michelle Araújo Ruiz, Milena Maria Cardoso de Lemos, Neila Soares Picanço, Rayara Gonzaga Maia, Regiane Carneiro Bezerra, Romeu Santos de Souza, Susy Cavalcante Harjani, Vitor Batista de Souza and Wellington Barbosa de Melo 


\section{Summary 30 words}

We report an intense infection transmission period that preceded the second wave of COVID-19 in Manaus, and identified several modifiable behaviors that increased the risk of seroconversion. 


\begin{abstract}
We report anti-SARS-CoV-2 nucleocapsid IgG seroconversion rates from a population-based cohort in Manaus, between August and November 2020, before the COVID-19 second wave in Brazil. Among seronegative and uninfected participants, we observed an overall incidence of $13.06 \%(95 \% \mathrm{Cl}, 11.52-14.79)$ and $6.78 \%$ $(95 \% \mathrm{Cl}, 5.61-8.10)$ for symptomatic seroconversion. Risk factors for seroconversion were: having a COVID-19 case in the household, not wearing a mask during contact, relaxation of protective measures, and non-remote work. We observed an intense infection transmission period that preceded the second wave of COVID-19 in Manaus, and identified several modifiable behaviors that increased the risk of seroconversion.
\end{abstract}

\title{
Main
}

Brazil ranks second in worldwide COVID-19 cases and deaths since the start of the pandemic ${ }^{1}$. The healthcare system in Manaus has collapsed twice in less than eight months, and the current second wave has surpassed the number of deaths and cases of the first wave (Figure 1a). The current high toll in morbidity and mortality is aggravating the precarious state in which the first wave left the region, with important consequences for the families and communities affected. In September 2020, several alerts were made regarding a possible second wave of infection if social distancing measures were relaxed ${ }^{2}$. However, social distancing rules were further relaxed, and their effects reflected on population mobility (Figure 1a); additionally, a research report on achieving herd immunity in Manaus could have further contributed to this behavior 3. In this report, we estimated the incidence and risk factors associated with SARSCoV-2 seroconversion from the DETECTCoV-19 cohort before the start of the second wave of infections in Manaus. 
In our previous cross-sectional baseline analysis of the DETECTCoV-19 cohort, we reported a crude seroprevalence of $29.10 \%$ in August $2020{ }^{4}$. From our initial recruitment cohort $(n=3057)$, a total of 2496 participants $(81.64 \%)$ returned for a second follow-up visit between 19/10/2020 and 27/11/2020 (Figure 1b). The crude anti-SARS-CoV-2 nucleocapsid IgG seropositivity at baseline, among the 2496 individuals that returned for follow-up was $27.72 \%(95 \% \mathrm{Cl}, 25.98-29.53)$, which increased to $34.33 \%(95 \% \mathrm{Cl}, 32.47-36.24)$ at the second visit. Test sensitivity- and specificity-adjusted antibody prevalence increased from $28.70 \%(95 \% \mathrm{Cl}, 26.70-$ $30.80)$ to $36.40 \%(95 \% \mathrm{Cl}, 34.30-38.60)$ after follow-up (Figure $1 \mathrm{~b})$. A paired analysis of anti-SARS-CoV-2 nucleocapsid-specific IgG Reactivity Index (RI) showed a significant increase at the second visit among the participants that returned for followup (Figure 1c). These findings indicate that the number of seropositive individuals and their IgG anti-nucleocapsid antibody RI levels were higher at follow-up (Figure 1c and 1e).

Next, we calculated the incidence of SARS-CoV-2 seroconversion. From the total participants evaluated at follow-up, 204 reported having COVID-19 infection prior to the first visit, and 24 had no data regarding this. From the remaining 2268, 1709 were IgG seronegative at first visit. Of them, 1424 had a $\mathrm{RI} \leq 1.5$ at the second visit and deemed still negative. Meanwhile, 214 had a $\mathrm{RI}>1.5$ with a $\mathrm{RI}$ ratio between the second and first visit $>2.0$, and were considered as seroconversion. Seventy-one participants had a second visit positive IgG, but did not meet the criteria of doubling the RI, thus were considered indeterminate and were not included in the analysis (Supplementary Figure 1). We found a high incidence of seroconversion at $13.06 \%$ 
$(95 \% \mathrm{Cl}, 11.52-14.79)$ with a median follow-up duration of 57 days (IQR, 54-61 days); in other words, $1 \%$ of the sample seroconverted every 4.5 days. Of these cases, $48.1 \%$ were asymptomatic; therefore, the incidence of symptomatic seroconversion was $6.78 \%(95 \% \mathrm{Cl} 5.61-8.10$, Figure 1d, Supplementary Table 1).

To our knowledge, this is the first study that reports SARS-CoV-2 seroconversion rates in a general population prospective cohort. Between the 1st and 2nd visit; only $2.93 \%$ of the sample had a positive RT-PCR test, and $5.43 \%$ developed symptoms and were diagnosed as COVID-19 (Supplementary Table 1). Between the start of the $1^{\text {st }}$ round collection and $2^{\text {nd }}$ round ending (August $19^{\text {th }}$ to November $27^{\text {th }}$ ), Manaus city Fundação de Vigilância em Saúde do Amazonas (FVS Amazonas) reported 30,278 RT-PCR positive cases (http://www.fvs.am.gov.br, date accessed 28 February, 2021), which correspond to a reporting rate of $1.36 \%(95 \% \mathrm{Cl}, 1.35-1.38)$. These results highlight the variations obtained using different case definition criteria; whereas it is seroconversion, symptomatic seroconversion, clinical diagnosis, diagnosis by PCR, or reporting to health agencies (Supplementary Table 1). Overall, it is important to timely identify the ratio between these divergent incidences and their dynamics during the pandemic in order to do adequate planning of resources and mitigation strategies. Our serology-based incidence rate, 5-10-fold higher than the official reports, indicates that the bulk of transmission prior to the second wave occurred mostly undetected by the current official survey methods.

We then analyzed the effect of sociodemographic, health-related, behavioral, case clustering, and COVID-19 testing on seroconversion (Supplementary Tables 2-4). In contrast with our previous report, which evaluated prevalence of seropositivity during 
August $2020^{4}$, this study looked at factors that affected incidence over a median twomonth period between August and November 2020. While in our first report, we found that prevalence was strongly associated with sociodemographic characteristics -as male sex, older age, lower income, occupation, and number of household members, these were no longer associated with the emergence of new cases during the study period. In contrast, we found that the main risk factors were related to the social behavior of the participants, such as not keeping social distance before August, relaxing social distancing after that, on-site working, and having contact with COVID19 patients without a mask (Figure 2, Supplementary Table 5). These results show that, between the first and second epidemic waves in Manaus, behavioral risk factors that increase exposure to SARS-CoV-2 were more important than biological or social characteristics as sex or poverty. Having a person with COVID-19 diagnosis in the household affected both the prevalence in August and the incidence in the following two-three months with similar magnitude. Crucially, independent of the moment of the pandemic, our findings confirm that having a COVID-19 contact in the household remains one of the more robust predictors for acquiring the disease ${ }^{5}$. Not surprisingly, having symptoms or having been diagnosed during the observation period were strongly associated with seroconversion, more so than in the cross-sectional study, underlying the correlation between these events.

Since the start of the pandemic effective surveillance, availability and ease of access to testing, well implemented non-pharmaceutical interventions (NPI) and the public health response measures linked to testing such as quarantine and isolation have been essential in controlling the virus transmission ${ }^{6-8}$. Our findings reveal that COVID19 index cases may have likely driven seroconversion -a representative proxy for 
infection burden- within the household, as observed in other high transmission settings ${ }^{9}$. Our data suggests that household close contacts of COVID-19 surviving or deceased patients should be tested regardless of symptoms and advised voluntary isolation 10; strict follow-up of cases and contacts is essential to reduce virus transmission ${ }^{6,11}$. NPI including social distancing, mask use and hygiene have been the pillar to reduce community SARS-CoV-2 transmission worldwide ${ }^{12}$. Therefore, lifting NPI abruptly diminishes the gains accumulated by previously implemented policies ${ }^{7,13}$. In our study, individuals who relaxed social distancing measures ${ }^{14}$ or had contact with COVID-19 individuals without mask ${ }^{15,16}$ had the highest risk of acquiring SARS-CoV-2 infection.

Our work has some limitations. A convenience sampling strategy based on on-line and university website advertising potentially excluded individuals who did not have access to this information and may not completely represent the general population. We also had shortcomings in performing active surveillance to identify symptomatic infections and positive RT-PCR tests results. Additionally, most symptomatic participants had a mild or moderate infection, but our surveillance method cannot exclude that severe illness cases and deaths occurred among the non-returning participants, underestimating total seroconversion events. Additionally, antibody response kinetics and their variability among populations limit our interpretations ${ }^{17}$. Despite these, our longitudinal serology approach to assess exposure and burden, and the size of our cohort, made possible in-depth statistical analysis to identify the risk factors associated with seroconversion in a setting of high transmission and low NPI containment measures. Unfortunately, we could not evaluate the role of the infecting SARS-CoV-2 strains. The cohort period between August and November 2020 
theoretically predates the surge and dominance of the P.1 (B.1.1.248) strain in the region ; however, we cannot rule out that the high rate of seroconversion in our cohort could have been influenced partially by the emergence of a more infectious strain, like the P.1 lineage in Manaus ${ }^{18,19}$. We hypothesize that the role of P.1 could be ascribed to accelerating the transmission rate observed after November, but we consider that the high seroconversion incidence found in our cohort might be explained by case clustering and host-related behavioral factors, as observed in high transmission settings ${ }^{5,9,20}$.

Rampant spread of SARS-CoV-2 infection in settings with low compliance to behavioral and NPI containment measures is a cause of concern due to its high human costs, elevated burden imposed on healthcare systems, and a possible impact on the emergence of new variants -favored in high transmission settings- which can negatively impact the effectiveness of available and future countermeasures including diagnostics, vaccines and therapeutics. This study provides timely actionable evidence for policymakers to inform next steps to mitigate the pandemic in Manaus and elsewhere. 
Figure legends

Figure 1: Anti-SARS-COV-2 nucleocapsid antibody prevalence and seroconversion before the second wave of infection from the DETECTCoV-19 cohort in Manaus.

(a) COVID-19 confirmed deaths (upper plot) and cases (middle plot), obtained from the Fundação de Vigilância em Saúde do Amazonas (http://www.fvs.am.gov.br, date accessed 28 February, 2021). Events following the SARS-CoV-2 pandemic were collated from the Amazonas state government website (http://www.amazonas.am.gov.br, date accessed 28 February, 2021); NPI-related, public health measures, and pandemic-related events depicted (text inserts, middle plot). Publicly available Google mobility data for Manaus city was obtained (https://www.google.com/covid19/mobility/, date accessed 01 March 2021) and plotted as percentage mobility change (lower plot). Crude and test-adjusted antiSARS-COV-2 nucleocapsid antibody seropositivity prevalence depicted as percentage of seropositive individuals for both study visits (whole cohort seroprevalence, upper plot; bars depict $95 \%$ Cl). (b) Seroprevalence in individuals that returned to second visit ( $n=2,496$; bars depict $95 \% \mathrm{Cl}$ ). (c) IgG Reactivity Index (RI) of paired samples from $1^{\text {st }}$ and $2^{\text {nd }}$ visits. Blue horizontal line denotes median values. Paired samples depicted by grey lines. (d) Seroconversion rates according to case definitions for symptomatic and asymptomatic (red) or asymptomatic-only individuals (black). (e) Paired RI of individuals who seroconverted as per study protocol. Red horizontal line denoted the median values in the violin plots. Dotted line at RI 1.5 denotes assay cut-off. Bars depict $95 \% \mathrm{Cl}$, dotted lines (c and d) depict IR cutoff $(\mathrm{IR}=1.5)$. 
Figure 2: Multivariate regression model for SARS-CoV-2 seroconversion in a general population cohort from Manaus, Amazonas state of Brazil $(\mathrm{N}=1,618)$. Forest Plot showing Incidence Rate Ratios (IRR) obtained via Poisson Regression considering follow-up time with robust variance corrected by clusters. IRRs are shown unadjusted and adjusted per all model variables (please refer Supplementary Table 5 for details). ${ }^{*}$ Not included in the multivariate model due to collinearity with the Household contact variable.

Supplementary Figure legend

Supplementary Figure 1: Flowchart for calculating incidence of SARS-CoV-2 seroconversion. 


\section{Methods}

Ethics and Study design

The research ethics committee of Federal University of Amazonas (UFAM) approved this study (CAAE:34906920.4.0000.5020) in accordance with Brazilian law, and the Helsinki declaration. All the participants gave oral and written consent prior to enrolment. This study followed the Strengthening the Reporting of Observational Studies in Epidemiology (STROBE) reporting guideline for cohort studies. A longitudinal study (DETECTCoV-19) in Manaus was designed to follow-up adults of both sexes $\geq 18$ years for up to 6 months after recruitment with a sample collection every 8-12 weeks as previously described ${ }^{4}$. A sample size of 2399 individuals was calculated to estimate seroprevalence with a $95 \% \mathrm{Cl}$ and $2 \%$ error.

\section{Recruitment and follow-up}

Among the 3,057 individuals recruited between 19/08/2020 and 02/10/2020, 2,496 individuals returned in person for the $2^{\text {nd }}$ visit between 19/10/2020 and 27/11/2020. All participants filled out an electronic questionnaire and donated a blood sample for the SARS-CoV-2 testing (Supplementary Figure 1).

At the second visit, we collected information related to social distancing, information related to COVID-19 disease, symptoms since the start of the pandemic, prior diagnosis, auto-medication and prescribed medication used for treatment of symptoms was recorded. Study participants presented oropharyngeal SARS-CoV-2 RT-PCR or antigen test reports performed by local government or private laboratories when available. We also recorded information about the COVID-19 cases in family and individual's residence. Finally, an independent form was used to record the SARSCoV-2 serological assay results. Trained interviewers collected participant data using 
the Research Electronic Data Capture (REDCap) software, an online web application with integrated quality checks (e.g., range and valid values, date formats, skip logic). The study used an online appointment system to reduce unnecessary gathering and followed all state and federal COVID-19-related regulations. The collection center was equipped with state-compliant measures for appropriate social distancing, and all members of the DETECTCoV-19 team used appropriate PPE. All state and federal COVID-19-related regulations were followed during the course of the study. All test results were communicated by email or via phone messaging to the study participants.

Serological testing

An indirect Enzyme Linked Immunosorbent Assay (ELISA)-based serological assay was used to measure anti-SARS-CoV-2 nucleocapsid IgG antibody levels in serum samples as previously described ${ }^{4}$. The in-house indirect anti-SARS-CoV-2 nucleocapsid IgG ELISA had a sensitivity of $94.28 \%(95 \% \mathrm{Cl}, 89.44-97.07)$, specificity of $97.03 \%(95 \% \mathrm{Cl}, 93.72-98.69)$ for patient with $\geq 14$ days after onset of COVID-19 symptoms. An anti-SARS-CoV-2 N IgG antibody reactivity index (RI) was expressed as the ratio between optical density of patient sample and negative control. All samples with a RI value above 1.5 (assay cut-off) were considered positive ${ }^{4}$.

Cohort definitions for calculating incidence of seroconversion Inclusion criteria: Patients of both sexes, 18 years old or above, who accepted to participate in the study and have at least two evaluations separated por at least four weeks.

Exclusion criteria: Patients who reported having a COVID-19 diagnosis prior to the first visit, either by PCR, serology, radiology, or clinical diagnosis. Patients who have no 
data or did not answer questions regarding COVID-19 diagnosis prior to the first visit. Patients who had IgG ELISA reactivity index $>1.5$ at the first visit.

Seroconversion Definition: Patients meeting the selection criteria who had IgG ELISA reactivity index $\leq 1.5$ at first visit, IgG ELISA reactivity index $>1.5$ at the second visit, and a reactivity index ratio (visit $2 /$ visit 1 ) $>2$.

Data analysis

Statistical analysis was performed using Stata version 14.0 (College Station, Texas). Participants who had an indeterminate seroconversion status were not included in the statistical analysis. Number of people in each category were listed in the first table column to show incidence denominators and account for variations due to missing data. Frequency distribution, cumulative incidence and incidence density (considering follow-up time) for seroconversion and for symptomatic seroconversion were calculated for the whole group and according to the study variables. Missing values were excluded from calculations, therefore were not listed as a separate category or into the incidence denominators. Chi-square or Fisher's exact tests were used to evaluate association between seroconversion incidences and independent variables. Also, Poisson regression models with robust variance corrected per clusters (administrative areas) was used to estimate crude Relative Risk (RR) and crude Incidence Rate Ratios (IRR) that considered follow-up time for each variable. A multivariate model estimating adjusted IRRs was constructed including age, sex, and all the variables that had significative association in the crude models. $P$ values $\leq 0.05$ were considered statistically significant. 


\section{Declaration of interests}

The authors declare no conflict of interest.

\section{Funding}

JDBL was supported by funds from the Ministry of Education (MEC), Brazil. PL received funding from the Fundação de Amparo à Pesquisa do Estado do Amazonas (FAPEAM). BBS, IVPF, ARCB and WBSS received scholarship from CAPES. DSSS, TBNM and MFF received scholarship from FAPEAM.

\section{Acknowledgement}

We would like to thank Comitê de Enfrentamento de Coronavírus/UFAM and Escola de Enfermagem de Manaus (EEM/UFAM) for the logistical support. We are also grateful to Laboratório Central de Saúde Pública do Amazonas (LACEN/AM) for providing SARS-CoV-2 RT-PCR testing. 


\section{References}

1. WHO. WHO Coronavirus (COVID-19) Dashboard. (2021). https://covid19.who.int

2. Ferrante, L., et al. Brazil's policies condemn Amazonia to a second wave of COVID-19. Nature Medicine 26, 1315-1315 (2020).

3. Buss, L.F., et al. Three-quarters attack rate of SARS-CoV-2 in the Brazilian Amazon during a largely unmitigated epidemic. Science (2020).

4. Lalwani, P., et al. SARS-CoV-2 Seroprevalence and Associated Factors in Manaus, Brazil: Baseline Results from the DETECTCoV-19 Cohort Study. SSRN Electronic Journal (2021). http://dx.doi.org/10.2139/ssrn.3795816

5. Madewell, Z.J., Yang, Y., Longini, I.M., Halloran, M.E. \& Dean, N.E. Household Transmission of SARS-CoV-2. JAMA Network Open 3(2020).

6. Lokuge, K., et al. Exit strategies: optimising feasible surveillance for detection, elimination, and ongoing prevention of COVID-19 community transmission. BMC Medicine 19(2021).

7. Singh, S., Shaikh, M., Hauck, K. \& Miraldo, M. Impacts of introducing and lifting nonpharmaceutical interventions on COVID-19 daily growth rate and compliance in the United States. Proceedings of the National Academy of Sciences 118, e2021359118 (2021).

8. Chu, D.K., et al. Physical distancing, face masks, and eye protection to prevent person-to-person transmission of SARS-CoV-2 and COVID-19: a systematic review and meta-analysis. The Lancet 395, 1973-1987 (2020).

9. Li, F., et al. Household transmission of SARS-CoV-2 and risk factors for susceptibility and infectivity in Wuhan: a retrospective observational study. The Lancet Infectious Diseases (2021).

10. Kucharski, A.J., et al. Effectiveness of isolation, testing, contact tracing, and physical distancing on reducing transmission of SARS-CoV-2 in different settings: a mathematical modelling study. The Lancet Infectious Diseases 20, 1151-1160 (2020).

11. Zhang, J., et al. Evolving epidemiology and transmission dynamics of coronavirus disease 2019 outside Hubei province, China: a descriptive and modelling study. The Lancet Infectious Diseases 20, 793-802 (2020).

12. Brauner, J.M., et al. Inferring the effectiveness of government interventions against COVID-19. Science 371(2021).

13. Oraby, T., et al. Modeling the effect of lockdown timing as a COVID-19 control measure in countries with differing social contacts. Scientific Reports 11(2021).

14. Tsai, A.C., Harling, G., Reynolds, Z., Gilbert, R.F. \& Siedner, M.J. Coronavirus Disease 2019 (COVID-19) Transmission in the United States Before Versus After Relaxation of Statewide Social Distancing Measures. Clinical Infectious Diseases (2020).

15. Howard, J., et al. An evidence review of face masks against COVID-19. Proceedings of the National Academy of Sciences 118(2021).

16. Leung, N.H.L., et al. Respiratory virus shedding in exhaled breath and efficacy of face masks. Nature Medicine 26, 676-680 (2020).

17. Amanat, F., et al. A serological assay to detect SARS-CoV-2 seroconversion in humans. Nature Medicine 26, 1033-1036 (2020). 
18. Naveca, F., et al. COVID-19 epidemic in the Brazilian state of Amazonas was driven by long-term persistence of endemic SARS-CoV-2 lineages and the recent emergence of the new Variant of Concern P.1. Research Square (2021).

19. Faria, N.R. Genomic characterisation of an emergent SARS-CoV-2 lineage in Manaus: preliminary findings. (https://virological.org/t/genomiccharacterisation-of-an-emergent-sars-cov-2-lineage-in-manaus-preliminaryfindings/586, 2021).

20. Del Brutto, O.H., et al. Household Clustering of SARS-CoV-2 in Community Settings: A Study from Rural Ecuador. The American Journal of Tropical Medicine and Hygiene 103, 1207-1210 (2020). 


\section{Figure 1}

A

Seroprevalence

$\rightarrow$ Manaus $\because$ Crude

- Amazonas state $\square$ Test-adjusted
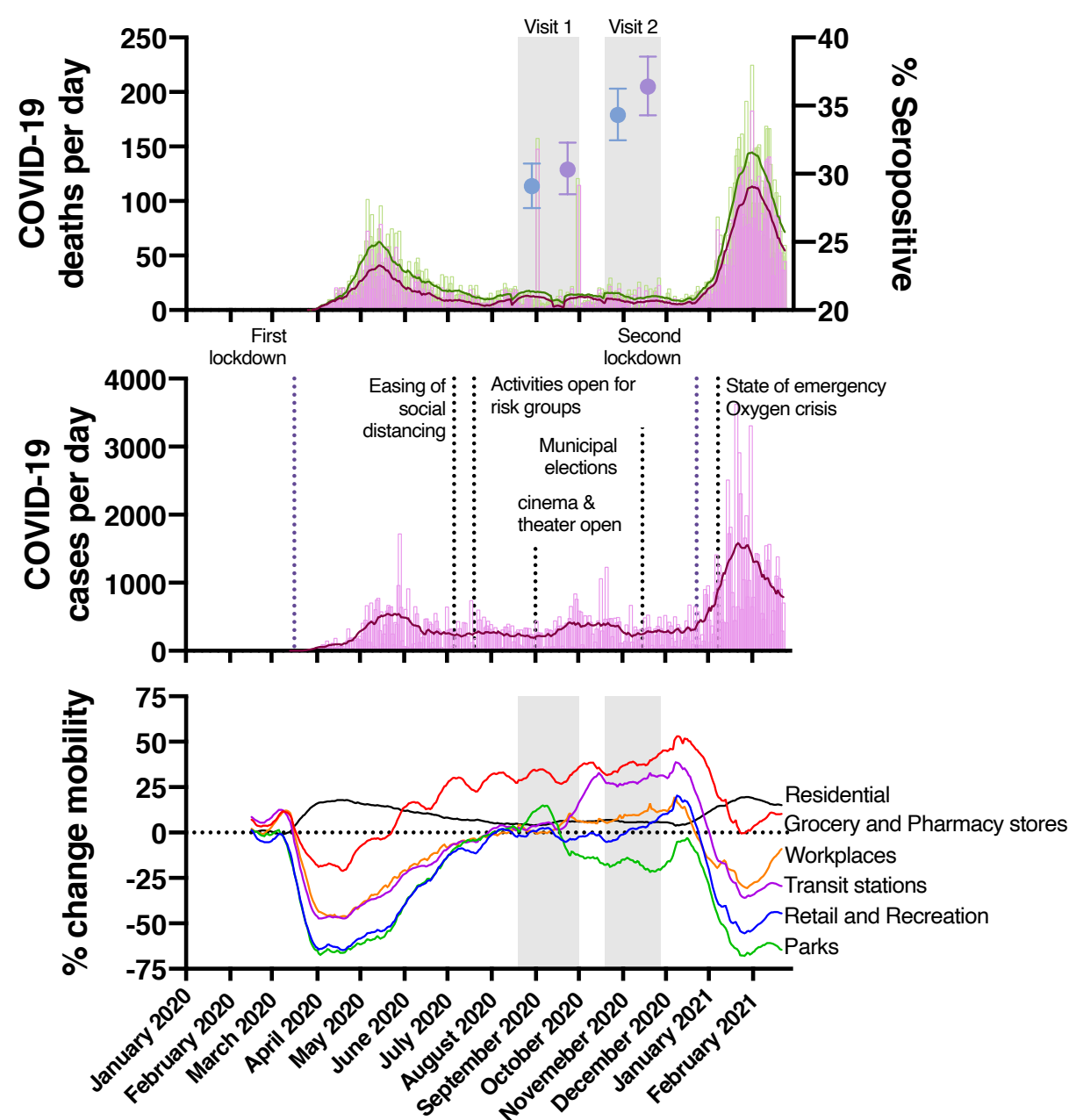

B

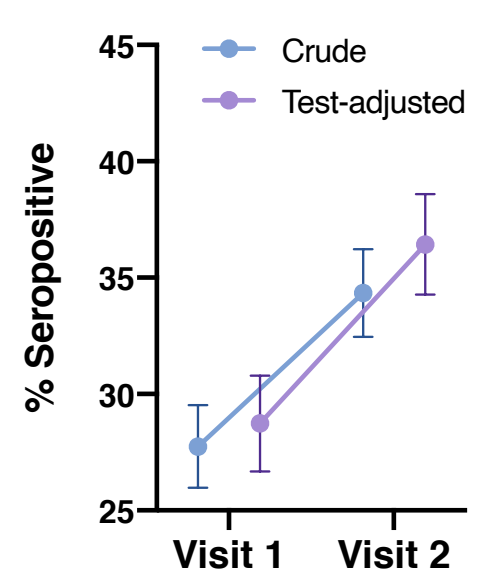

D

- Symptomatic-only

- Symptomatic or Asymptomatic PCR only-1 PCR and/or Antigen and/or Antigen TestAny Lab result and/or Clinical/Radiology DxSeroconversion as per Study-

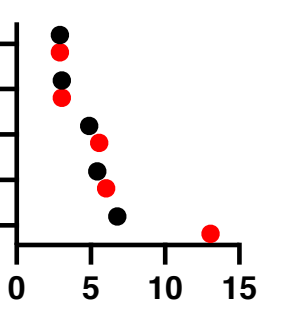

Seroconversion rate (\%)
C

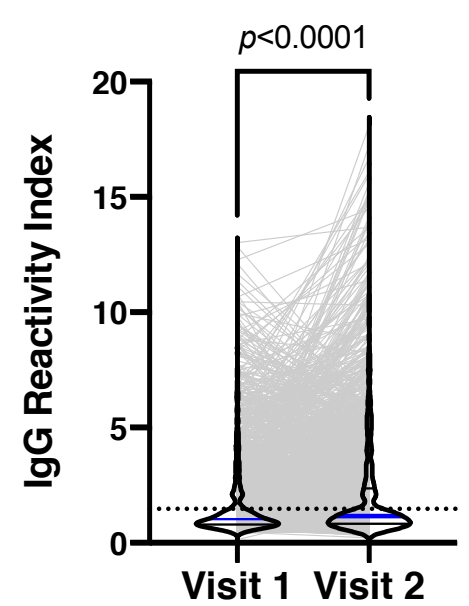

E

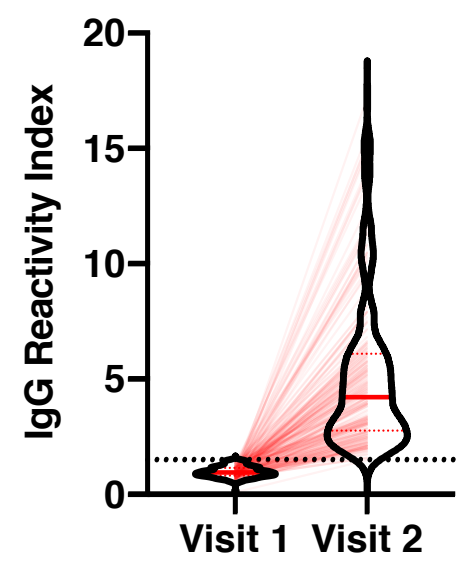


Social distancing (before August): Sometimes Frequently

Social distancing flexibilization (since August): Yes

Work (before August): Remote only Family members with COVID-19 (until $2^{\text {nd }}$ visit)*: Yes, alive Yes, deaths Household members with COVID-19 (until $2^{\text {nd }}$ visit): Yes, alive Yes, deaths COVID-19 Contacts (since August): Yes, with mask Yes, without mask Symptoms (since August): Flu-like Other COVID-19 Diagnosis (since August): Yes

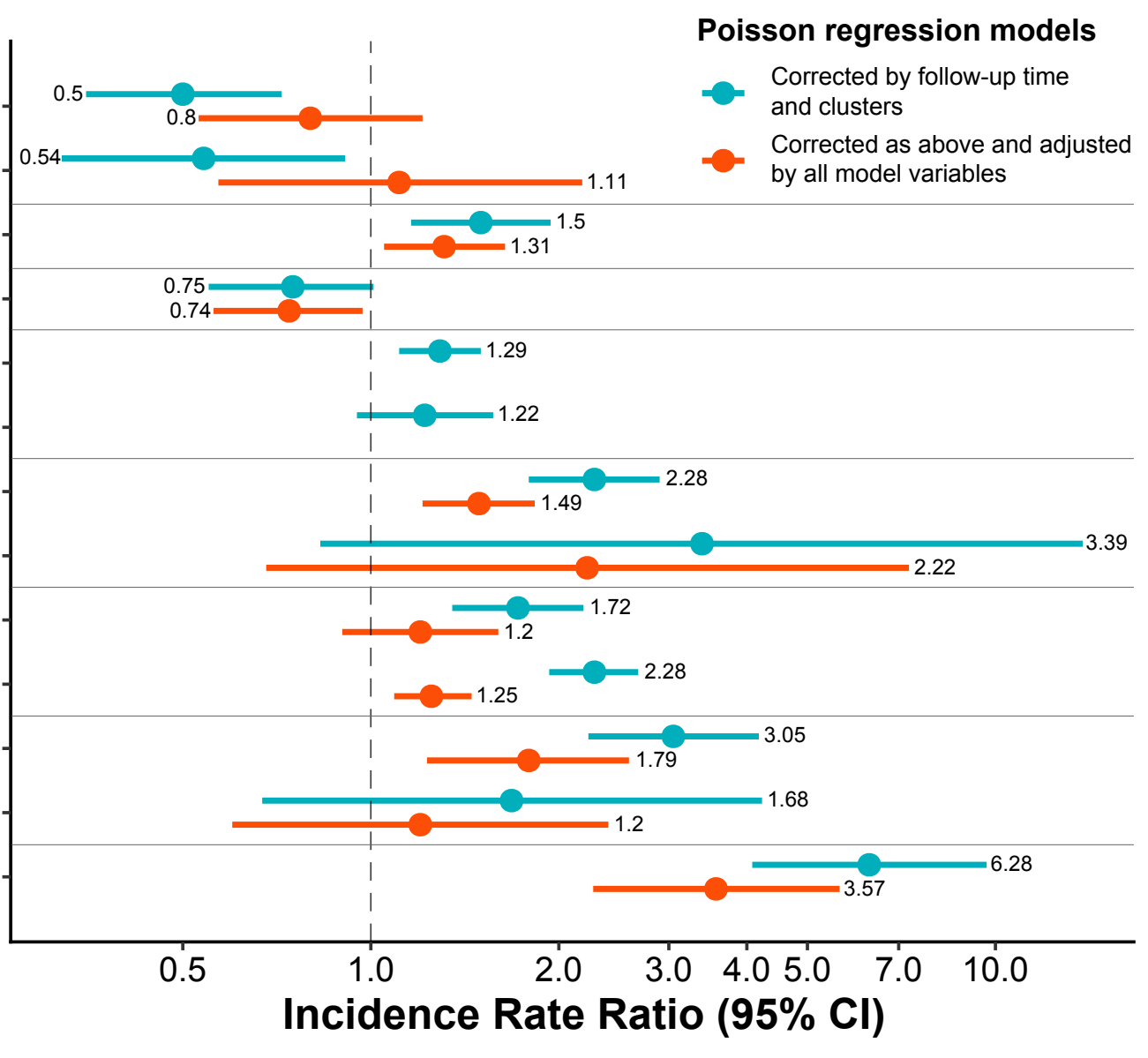


Supplementary Table 1: Comparison of SARS-CoV-2 seroconversion rates using different Case Definitions in a general population cohort from Manaus, Amazonas state of Brazil $(\mathrm{N}=1,638)$.

\begin{tabular}{|l|c|c|c|c|}
\hline $\begin{array}{l}\text { Case Definition between } \mathbf{1}^{\text {st }} \text { and 2 } \\
\mathbf{N}=\mathbf{1 6 3 8}\end{array}$ & \multicolumn{2}{|c|}{$\begin{array}{c}\text { Symptomatic } \\
\text { Only }\end{array}$} & \multicolumn{2}{c|}{$\begin{array}{c}\text { Symptomatic or } \\
\text { Asymptomatic }\end{array}$} \\
\hline & $\mathbf{n}$ & $\mathbf{( \% )}$ & $\mathbf{n}$ & $\mathbf{( \% )}$ \\
\hline PCR only & 48 & $(2.93)$ & 48 & $(2.93)$ \\
\hline PCR and/or Antigen Test & 50 & $(3.05)$ & 50 & $(3.05)$ \\
\hline PCR and/or Antigen and/or Serological Test & 80 & $(4.88)$ & 91 & $(5.56)$ \\
\hline Any Lab result and/or Clinical/Radiology Dx & 89 & $(5.43)$ & 99 & $(6.04)$ \\
\hline Seroconversion as per Study & 111 & $(6.78)$ & 214 & $(13.06)$ \\
\hline
\end{tabular}


Supplementary Table 2: SARS-CoV-2 seroconversion according to Demographics and Health access characteristics of a general population cohort from Manaus, Amazonas state of Brazil $(\mathrm{N}=1,638)$.

\begin{tabular}{|c|c|c|c|c|c|c|c|c|c|c|c|c|}
\hline Characteristics $^{1}$ & Categories & Total & $\underset{\%}{\text { column }}$ & $\begin{array}{c}\text { IgG } \\
\text { ELISA } \\
(-) \text {-> (+) }\end{array}$ & $\begin{array}{c}\text { Incidence } \\
\text { row } \%\end{array}$ & $\begin{array}{c}\text { p value } \\
\text { Chi2 } \\
\text { test }\end{array}$ & $\mathbf{R R}^{*}$ & $95 \% \mathrm{Cl}$ & $\begin{array}{l}p \\
\text { value }\end{array}$ & IRR $^{* *}$ & $95 \% \mathrm{Cl}$ & $\begin{array}{l}\mathbf{p} \\
\text { value }\end{array}$ \\
\hline Total & & 1,638 & & 214 & 13.06 & & & & & & & \\
\hline \multicolumn{13}{|l|}{ Demographics } \\
\hline \multirow[t]{5}{*}{ Age } & $18-29$ & 372 & 22.71 & 48 & 12.90 & 0.915 & Ref & ----- & ----- & Ref & ----- & ----- \\
\hline & $30-39$ & 420 & 25.64 & 56 & 13.33 & & 1.03 & $0.68-1.57$ & 0.878 & 1.00 & $0.66-1.51$ & 0.990 \\
\hline & $40-49$ & 354 & 21.61 & 48 & 13.56 & & 1.05 & $0.81-1.36$ & 0.703 & 1.02 & $0.80-1.31$ & 0.865 \\
\hline & $50-59$ & 292 & 17.83 & 40 & 13.70 & & 1.06 & $0.69-1.63$ & 0.786 & 1.02 & $0.66-1.57$ & 0.924 \\
\hline & $>=60$ & 200 & 12.21 & 22 & 11.00 & & 0.85 & $0.37-1.99$ & 0.712 & 0.82 & $0.36-1.90$ & 0.648 \\
\hline \multirow[t]{2}{*}{ Sex } & $\mathrm{F}$ & 1,031 & 62.94 & 130 & 12.61 & 0.476 & Ref & ----- & +---- & Ref & ---- & ----- \\
\hline & $\mathrm{M}$ & 607 & 37.06 & 84 & 13.84 & & 1.10 & $0.75-1.60$ & 0.627 & 1.08 & $0.75-1.56$ & 0.663 \\
\hline \multirow[t]{5}{*}{ Race } & Mestizo & 885 & 54.03 & 125 & 14.12 & 0.290 & Ref & ---- & ---- & Ref & ---- & ----- \\
\hline & White & 602 & 36.75 & 74 & 12.29 & & 0.87 & $0.57-1.32$ & 0.515 & 0.89 & $0.58-1.35$ & 0.570 \\
\hline & Black & 109 & 6.65 & 9 & 8.26 & & 0.58 & $0.12-2.81$ & 0.503 & 0.59 & $0.12-2.81$ & 0.509 \\
\hline & Indigenous & 7 & 0.43 & 0 & 0.00 & & NA & & & NA & & \\
\hline & East-Asian & 35 & 2.14 & 6 & 17.14 & & 1.21 & $0.51-2.90$ & 0.663 & 1.25 & $0.52-3.02$ & 0.622 \\
\hline \multirow[t]{3}{*}{ Marital status } & Married/Stable Union & 748 & 45.86 & 97 & 12.97 & 0.593 & Ref & ----- & ---- & Ref & ----- & ----- \\
\hline & Divorced/Widow & 151 & 9.26 & 16 & 10.61 & & 0.82 & $0.52-1.28$ & 0.378 & 0.82 & $0.54-1.26$ & 0.368 \\
\hline & Single & 732 & 44.88 & 100 & 13.66 & & 1.05 & $0.80-1.38$ & 0.708 & 1.08 & $0.83-1.41$ & 0.568 \\
\hline \multirow[t]{2}{*}{ Sexual Orientation } & Heterosexual & 1,441 & 89.78 & 182 & 12.63 & 0.167 & Ref & ----- & ---- & Ref & ----- & ----- \\
\hline & Homo-/Bi-/Transsexual & 164 & 10.22 & 27 & 16.46 & & 1.30 & $0.84-2.02$ & 0.234 & 1.33 & $0.86-2.04$ & 0.195 \\
\hline \multirow[t]{4}{*}{ Occupation } & Professional Higher & 974 & 60.12 & 121 & 12.42 & 0.667 & Ref & ----- & ----- & Ref & ----- & ----- \\
\hline & Professional Middle & 163 & 10.06 & 22 & 13.50 & & 1.08 & $0.59-2.00$ & 0.790 & 1.08 & $0.59-1.95$ & 0.807 \\
\hline & Worker/Informal & 296 & 18.27 & 45 & 15.20 & & 1.22 & $0.94-1.60$ & 0.136 & 1.21 & $0.91-1.60$ & 0.198 \\
\hline & Unemployed & 187 & 11.54 & 25 & 13.37 & & 1.08 & $0.81-1.44$ & 0.618 & 1.12 & $0.84-1.48$ & 0.435 \\
\hline \multirow[t]{2}{*}{ Healthcare Job } & No & 1,380 & 84.25 & 179 & 12.97 & 0.795 & Ref & ----- & ----- & Ref & ----- & ---- \\
\hline & Yes & 258 & 15.75 & 35 & 13.57 & & 1.05 & $0.73-1.50$ & 0.807 & 1.00 & $0.69-1.45$ & 1.000 \\
\hline \multirow[t]{3}{*}{ Family Income } & $>6$ minimum wages & 731 & 45.57 & 96 & 13.13 & 0.713 & Ref & ----- & ----- & Ref & ---- & ----- \\
\hline & 4-6 minimum wages & 390 & 24.31 & 55 & 14.10 & & 1.07 & $0.79-1.46$ & 0.647 & 1.10 & $0.81-1.48$ & 0.537 \\
\hline & $0-3$ minimum wages & 483 & 30.11 & 59 & 12.22 & & 0.93 & $0.77-1.13$ & 0.466 & 0.95 & $0.78-1.16$ & 0.603 \\
\hline \multirow[t]{3}{*}{ Housing } & Apartment & 550 & 33.78 & 71 & 12.91 & 0.438 & Ref & ---- & ---- & Ref & ---- & ----- \\
\hline & Condo/Conjugated & 303 & 18.61 & 46 & 15.18 & & 1.18 & $0.98-1.42$ & 0.089 & 1.17 & $0.97-1.40$ & 0.098 \\
\hline & Detached house & 775 & 47.60 & 95 & 12.26 & & 0.95 & $0.71-1.27$ & 0.724 & 0.95 & $0.71-1.27$ & 0.717 \\
\hline
\end{tabular}




\begin{tabular}{|c|c|c|c|c|c|c|c|c|c|c|c|c|}
\hline Number Adults in & 1 & 156 & 9.59 & 22 & 14.10 & 0.883 & Ref & ----- & ----- & Ref & ----- & ----- \\
\hline \multirow[t]{3}{*}{ residence } & 2 & 633 & 38.91 & 86 & 13.59 & & 0.96 & $0.65-1.43$ & 0.852 & 0.94 & $0.64-1.39$ & 0.758 \\
\hline & 3 & 419 & 25.75 & 53 & 12.65 & & 0.90 & $0.59-1.37$ & 0.614 & 0.90 & $0.60-1.36$ & 0.623 \\
\hline & $4+$ & 419 & 25.75 & 51 & 12.17 & & 0.86 & $0.64-1.16$ & 0.336 & 0.87 & $0.64-1.19$ & 0.390 \\
\hline Number Children in & 0 & 1,006 & 62.37 & 129 & 12.82 & 0.970 & Ref & ----- & ----- & Ref & ----- & ----- \\
\hline \multirow[t]{3}{*}{ residence } & 1 & 395 & 24.49 & 52 & 13.16 & & 1.03 & $0.74-1.42$ & 0.873 & 1.01 & $0.72-1.41$ & 0.950 \\
\hline & 2 & 173 & 10.73 & 23 & 13.29 & & 1.04 & $0.59-1.81$ & 0.899 & 1.01 & $0.59-1.73$ & 0.969 \\
\hline & $3+$ & 39 & 2.42 & 6 & 15.38 & & 1.20 & $0.43-3.35$ & 0.728 & 1.20 & $0.42-3.42$ & 0.737 \\
\hline Administrative & Center-South & 581 & 35.47 & 84 & 10.50 & 0.015 & NA & & & NA & & \\
\hline \multirow[t]{5}{*}{ zones } & Center-West & 148 & 9.04 & 28 & 16.22 & & NA & & & NA & & \\
\hline & East & 163 & 9.95 & 31 & 13.50 & & NA & & & NA & & \\
\hline & North & 274 & 16.73 & 46 & 10.22 & & NA & & & NA & & \\
\hline & West & 169 & 10.32 & 38 & 19.53 & & NA & & & NA & & \\
\hline & South & 303 & 18.50 & 58 & 15.18 & & NA & & & NA & & \\
\hline \multicolumn{13}{|l|}{ HealthCare Access } \\
\hline \multirow[t]{2}{*}{ Private Insurance } & No & 609 & 37.20 & 89 & 14.61 & 0.154 & Ref & ----- & ----- & Ref & ----- & ----- \\
\hline & Yes & 1,028 & 62.80 & 125 & 12.16 & & 0.83 & $0.59-1.18$ & 0.302 & 0.83 & $0.59-1.17$ & 0.295 \\
\hline \multirow[t]{4}{*}{ Influenza Vaccine } & Last time 2020 & 806 & 49.21 & 96 & 11.91 & 0.128 & Ref & ----- & ----- & Ref & ----- & ----- \\
\hline & Last time 2019 & 371 & 22.65 & 62 & 16.71 & & 1.40 & $0.98-2.01$ & 0.065 & 1.41 & 0.98-2.01 & 0.064 \\
\hline & Prior to 2019 & 306 & 18.68 & 38 & 12.42 & & 1.04 & $0.66-1.64$ & 0.857 & 1.04 & $0.66-1.66$ & 0.861 \\
\hline & Never & 155 & 9.46 & 18 & 11.61 & & 0.98 & $0.57-1.68$ & 0.928 & 0.99 & $0.57-1.69$ & 0.958 \\
\hline
\end{tabular}

${ }^{1}$ Variables obtained at $1^{\text {st }}$ Cohort Visit except when indicated.

* Relative Risk (RR) using Poisson Regression with robust variance corrected by clusters.

** Incidence Rate Ratio (IRR) using Poisson Regression considering follow-up time with robust variance corrected by clusters. 
Supplementary Table 3: SARS-CoV-2 seroconversion according to COVID-19 Risk Factors and Exposures in a general population cohort from Manaus, Amazonas state of Brazil $(\mathrm{N}=1,638)$.

\begin{tabular}{|c|c|c|c|c|c|c|c|c|c|c|c|c|}
\hline Characteristics $^{1}$ & Variables & Total & $\underset{\%}{\text { Column }}$ & $\begin{array}{c}\text { IgG } \\
\text { ELISA } \\
(-) \text {-> (+) }\end{array}$ & $\begin{array}{c}\text { Incidence } \\
\%\end{array}$ & $\begin{array}{c}\text { p value } \\
\text { Chi2 } \\
\text { test }\end{array}$ & $\mathbf{R R}^{* *}$ & $95 \% \mathrm{Cl}$ & $\begin{array}{l}p \\
\text { value }\end{array}$ & IRR ${ }^{* * *}$ & $95 \% \mathrm{Cl}$ & $\begin{array}{l}p \\
\text { value }\end{array}$ \\
\hline Total & & 1,638 & & 214 & 13.06 & & & & & & & \\
\hline \multicolumn{13}{|l|}{ Risk Factors } \\
\hline \multirow[t]{2}{*}{ Pregnancy } & No & 1,022 & 99.13 & 130 & 12.72 & $0.612^{*}$ & $\mathrm{NA}$ & & & $\mathrm{NA}$ & & \\
\hline & Yes & 9 & 0.87 & 0 & 0.00 & & & & & & & \\
\hline \multirow[t]{2}{*}{ Comorbidities (any) } & No & 967 & 59.04 & 130 & 13.44 & 0.585 & Ref & ----- & ----- & Ref & ----- & ----- \\
\hline & Yes & 671 & 40.96 & 84 & 12.52 & & 0.93 & $0.66-1.31$ & 0.683 & 0.94 & $0.66-1.33$ & 0.723 \\
\hline \multirow[t]{8}{*}{ Which Comorbidities } & Chronic Respiratory & 152 & 9.28 & 25 & 16.45 & & 1.22 & $0.83-1.80$ & 0.308 & 1.22 & $0.82-1.82$ & 0.323 \\
\hline & Diabetes & 91 & 5.56 & 14 & 15.38 & & 1.14 & $0.75-1.74$ & 0.528 & 1.13 & $0.73-1.75$ & 0.589 \\
\hline & Obesity & 112 & 6.84 & 19 & 16.96 & & 1.26 & $0.80-2.00$ & 0.320 & 1.24 & $0.76-2.02$ & 0.384 \\
\hline & Hypertension & 250 & 15.26 & 28 & 11.20 & & 0.83 & $0.59-1.17$ & 0.297 & 0.84 & $0.59-1.19$ & 0.331 \\
\hline & Cardiopathy & 105 & 6.41 & 11 & 10.48 & & 0.80 & $0.48-1.26$ & 0.308 & 0.79 & $0.49-1.29$ & 0.352 \\
\hline & Chronic Renal & 30 & 1.83 & 6 & 20.00 & & 1.49 & $0.98-2.26$ & 0.063 & 1.46 & $0.97-2.22$ & 0.071 \\
\hline & Immunological & 30 & 1.83 & 6 & 20.00 & & 1.49 & $0.70-3.15$ & 0.299 & 1.53 & $0.74-3.16$ & 0.256 \\
\hline & Cancer & 8 & 0.49 & 0 & 0.00 & & NA & & & NA & & \\
\hline Preventive Self & None/Vit/Homemade & 1,359 & 82.97 & 168 & 12.36 & 0.140 & Ref & ----- & ----- & Ref & ----- & ----- \\
\hline \multirow[t]{2}{*}{ medication (any) } & Over the counter & 110 & 6.72 & 20 & 18.18 & & 1.47 & $0.90-2.40$ & 0.122 & 1.47 & $0.89-2.44$ & 0.132 \\
\hline & Prescription Meds & 169 & 10.32 & 26 & 15.38 & & 1.24 & $0.91-1.70$ & 0.166 & 1.26 & $0.92-1.73$ & 0.153 \\
\hline \multirow[t]{5}{*}{ Which medication } & Nitazoxanide & 17 & 1.04 & 2 & 11.76 & & NA & & & NA & & \\
\hline & Azithromycin & 53 & 3.24 & 10 & 18.87 & & $\mathrm{NA}$ & & & NA & & \\
\hline & Hydroxy/Chloroquine & 4 & 0.24 & 1 & 25.00 & & NA & & & NA & & \\
\hline & Corticosteroids & 14 & 0.85 & 2 & 14.29 & & NA & & & NA & & \\
\hline & Ivermectin & 130 & 7.94 & 28 & 13.08 & & NA & & & NA & & \\
\hline \multicolumn{13}{|l|}{ COVID-19 Exposure } \\
\hline Social Distancing & Never & 29 & 1.79 & 7 & 24.14 & 0.183 & Ref & ----- & ----- & Ref & ----- & ----- \\
\hline \multirow[t]{2}{*}{ before August } & Sometimes & 417 & 25.74 & 51 & 12.23 & & 0.51 & $0.36-0.72$ & $<0.001$ & 0.50 & $0.35-0.72$ & $<0.001$ \\
\hline & Frequently & 1,174 & 72.47 & 153 & 13.03 & & 0.54 & $0.33-0.88$ & 0.014 & 0.54 & $0.32-0.91$ & 0.022 \\
\hline \multirow[t]{2}{*}{ Flexibilization August } & No & 257 & 15.86 & 24 & 9.34 & 0.056 & Ref & ---- & ---- & Ref & ---- & ---- \\
\hline & Yes & 1,363 & 84.14 & 187 & 13.72 & & 1.47 & 1.14-1.89 & 0.003 & 1.50 & $1.16-1.94$ & 0.002 \\
\hline \multirow[t]{3}{*}{ Work before August } & On-site & 479 & 29.55 & 79 & 16.49 & 0.014 & Ref & ---- & ----- & Ref & ---- & ----- \\
\hline & Remote Only & 780 & 48.12 & 96 & 12.31 & & 0.75 & $0.55-1.01$ & 0.058 & 0.75 & $0.55-1.01$ & 0.059 \\
\hline & NA & 362 & 22.33 & 36 & 9.94 & & & & & & & \\
\hline
\end{tabular}




\begin{tabular}{|c|c|c|c|c|c|c|c|c|c|c|c|c|}
\hline Work since August & On-site & 765 & 47.25 & 105 & 13.73 & 0.161 & Ref & ----- & ----- & Ref & ----- & ----- \\
\hline & Only Remote & 580 & 35.82 & 80 & 13.79 & & 1.00 & $0.84-1.20$ & 0.957 & 0.98 & $0.82-1.18$ & 0.867 \\
\hline & NA & 274 & 16.92 & 26 & 9.49 & & & & & & & \\
\hline Family members with & No & 495 & 30.22 & 54 & 10.91 & 0.228 & Ref & ----- & ----- & Ref & ----- & ----- \\
\hline \multirow[t]{2}{*}{ COVID-19 (at $\left.2^{\text {nd }}\right)$} & Yes, alive & 892 & 54.46 & 126 & 14.13 & & 1.29 & 1.11-1.51 & 0.001 & 1.29 & 1.11-1.50 & 0.001 \\
\hline & Yes, deaths & 251 & 15.32 & 34 & 13.55 & & 1.24 & $0.97-1.59$ & 0.087 & 1.22 & $0.95-1.57$ & 0.116 \\
\hline Household members & No & 1,261 & 76.98 & 127 & 10.07 & $<0.001^{*}$ & Ref & ----- & ----- & Ref & ----- & ----- \\
\hline \multirow[t]{2}{*}{ COVID-19 (at $\left.2^{\text {nd }}\right)$} & Yes, alive & 371 & 22.65 & 85 & 22.91 & & 2.27 & $1.78-2.91$ & $<0.001$ & 2.28 & $1.79-2.90$ & $<0.001$ \\
\hline & Yes, deaths & 6 & 0.37 & 2 & 33.33 & & 3.31 & $0.86-12.7$ & 0.081 & 3.39 & $0.83-13.8$ & 0.089 \\
\hline COVID-19 Contacts & None & 778 & 48.02 & 70 & 9.00 & $<0.001$ & Ref & ---- & ----- & Ref & ----- & ----- \\
\hline \multirow[t]{2}{*}{ Since August } & Yes, with Mask & 604 & 37.28 & 93 & 15.40 & & 1.71 & $1.36-2.16$ & $<0.001$ & 1.72 & $1.35-2.19$ & $<0.001$ \\
\hline & Yes, without Mask & 238 & 14.69 & 48 & 20.17 & & 2.24 & 1.93-2.61 & $<0.001$ & 2.28 & 1.93-2.68 & $<0.001$ \\
\hline
\end{tabular}

${ }^{1}$ Variables obtained at $1^{\text {st }}$ Cohort Visit except when indicated.

* Fisher's Exact Test

** Relative Risk (RR) using Poisson Regression with robust variance corrected by clusters.

*** Incidence Rate Ratio (IRR) using Poisson Regression considering follow-up time with robust variance corrected by clusters. 
Supplementary Table 4: SARS-CoV-2 seroconversion according to COVID-19 Symptoms and Diagnosis in a general population cohort from Manaus, Amazonas state of Brazil $(\mathrm{N}=1,638)$.

\begin{tabular}{|c|c|c|c|c|c|c|c|c|c|c|c|c|}
\hline Characteristics $^{1}$ & Variables & Total & $\begin{array}{l}\text { Column } \\
\%\end{array}$ & $\begin{array}{l}\text { IgG } \\
\text { ELISA } \\
(-)->(+)\end{array}$ & $\begin{array}{l}\text { Incidence } \\
\%\end{array}$ & $\begin{array}{l}p \text { value } \\
\text { Chi2 } \\
\text { test }\end{array}$ & $\mathrm{RR}^{* *}$ & $95 \% \mathrm{Cl}$ & $\begin{array}{l}\mathbf{p} \\
\text { value }\end{array}$ & IRR $\mathbf{R}^{\star * *}$ & $95 \% \mathrm{Cl}$ & $\begin{array}{l}\mathbf{p} \\
\text { value }\end{array}$ \\
\hline Total & & 1,638 & & 214 & 13.06 & & & & & & & \\
\hline \multicolumn{13}{|l|}{ Symptoms } \\
\hline Symptoms & None & 1,196 & 73.02 & 103 & 8.61 & $<0.001$ & Ref & ----- & ----- & Ref & ----- & ----- \\
\hline \multirow[t]{2}{*}{ (Between $1^{\text {st }} 2^{\text {nd }}$ visit) } & Flu-like & 393 & 23.99 & 104 & 26.46 & & 3.07 & $2.25-4.19$ & $<0.001$ & 3.05 & $2.23-4.18$ & $<0.001$ \\
\hline & Others & 49 & 2.99 & 7 & 14.29 & & 1.66 & $0.67-4.14$ & 0.277 & 1.68 & $0.67-4.23$ & 0.271 \\
\hline \multicolumn{13}{|l|}{$\begin{array}{l}\text { COVID-19 } \\
\text { Diagnosis }\end{array}$} \\
\hline PCR (Between & Not done & 1,487 & 92.13 & 161 & 10.83 & $<0.001$ & Ref & ----- & $\begin{array}{ll}----- \\
\end{array}$ & Ref & ----- & ----- \\
\hline \multirow[t]{2}{*}{$1^{\text {st }} 2^{\text {nd }}$ visit) } & Yes, Negative & 79 & 4.89 & 11 & 13.92 & & 1.29 & $0.85-1.96$ & 0.240 & 1.27 & $0.83-1.95$ & 0.269 \\
\hline & Yes, Positive & 48 & 2.97 & 36 & 75.00 & & 6.93 & $5.54-8.66$ & $<0.001$ & 6.70 & $5.28-8.51$ & $<0.001$ \\
\hline Serology (Between & Not done & 1,030 & 63.74 & 116 & 11.26 & $<0.001$ & Ref & ----- & ----- & Ref & ----- & $\begin{array}{ll}---- \\
\end{array}$ \\
\hline \multirow[t]{2}{*}{$1^{\text {st }} 2^{\text {nd }}$ visit) } & Yes, Negative & 531 & 32.86 & 63 & 11.86 & & 1.05 & $0.77-1.44$ & 0.743 & 1.08 & $0.80-1.47$ & 0.607 \\
\hline & Yes, Positive & 55 & 3.40 & 32 & 58.18 & & 5.17 & $3.31-8.06$ & $<0.001$ & 5.02 & $3.25-7.75$ & $<0.001$ \\
\hline Antigenic Test & Not done & 1,088 & 98.64 & 124 & 11.40 & $<0.001^{*}$ & Ref & ----- & ----- & Ref & ----- & ----- \\
\hline \multirow[t]{2}{*}{ (Between $1^{\text {st }} 2^{\text {nd }}$ visit) } & Yes, Negative & 9 & 0.82 & 1 & 11.11 & & 0.97 & $0.15-6.50$ & 0.979 & 1.11 & $0.16-7.71$ & 0.916 \\
\hline & Yes, Positive & 6 & 0.54 & 6 & 100.00 & & 8.77 & 6.61-11.7 & $<0.001$ & 8.90 & $6.60-12.0$ & $<0.001$ \\
\hline COVID-19 (Between & No & 1,538 & 93.95 & 151 & 9.82 & $<0.001$ & Ref & ----- & ----- & Ref & ----- & $\begin{array}{ll}---- \\
--\end{array}$ \\
\hline $1^{\text {st }} 2^{\text {nd }}$ visit) & Yes & 99 & 6.05 & 63 & 63.64 & & 6.48 & 4.24-9.90 & $<0.001$ & 6.28 & 4.08-9.68 & $<0.001$ \\
\hline
\end{tabular}

${ }^{1}$ Variables obtained at $1^{\text {st }}$ Cohort Visit except when indicated.

* Fisher's Exact Test

${ }^{* *}$ Relative Risk (RR) using Poisson Regression with robust variance corrected by clusters.

*** Incidence Rate Ratio (IRR) using Poisson Regression considering follow-up time with robust variance corrected by clusters. 
Supplementary Table 5: Multivariate Regression Model for SARS-CoV-2 seroconversion in a general population cohort from Manaus, Amazonas state of Brazil $(\mathrm{N}=1,618)$.

\begin{tabular}{|c|c|c|c|c|}
\hline Characteristics $^{1}$ & Variables & IRR* & $95 \% \mathrm{Cl}$ & $p$ value \\
\hline \multirow[t]{5}{*}{ Age } & $18-29$ & Ref & ----- & ----- \\
\hline & $30-39$ & 0.97 & $0.68-1.37$ & 0.854 \\
\hline & $40-49$ & 1.05 & $0.81-1.36$ & 0.725 \\
\hline & $50-59$ & 1.13 & $0.66-1.93$ & 0.652 \\
\hline & $>=60$ & 1.17 & $0.55-2.51$ & 0.683 \\
\hline \multirow[t]{2}{*}{ Sex } & $\mathrm{F}$ & Ref & ---- & ---- \\
\hline & $\mathrm{M}$ & 1.13 & $0.82-1.56$ & 0.458 \\
\hline Social Distancing & Never & Ref & ----- & ----- \\
\hline \multirow[t]{2}{*}{ before August } & Sometimes & 0.80 & $0.53-1.21$ & 0.285 \\
\hline & Frequently & 1.11 & $0.57-2.18$ & 0.758 \\
\hline SD Flexibilization & No & Ref & ----- & ----- \\
\hline since August & Yes & 1.31 & 1.05-1.64 & 0.017 \\
\hline \multirow{3}{*}{ Work before August } & On-site & Ref & ----- & +---- \\
\hline & Remote Only & 0.74 & $0.56-0.97$ & 0.030 \\
\hline & NA & & & \\
\hline Household members & No & Ref & ----- & ----- \\
\hline \multirow[t]{2}{*}{ with COVID-19 $\left(2^{\text {nd }}\right)$} & Yes, alive & 1.49 & 1.21-1.83 & $<0.001$ \\
\hline & Yes, deaths & 2.22 & $0.68-7.27$ & 0.186 \\
\hline COVID-19 Contacts & None & Ref & ----- & ----- \\
\hline \multirow[t]{2}{*}{ since August } & Yes, with Mask & 1.20 & $0.90-1.60$ & 0.219 \\
\hline & Yes, without Mask & 1.25 & 1.09-1.45 & 0.002 \\
\hline Symptoms since & None & Ref & ---- & +---- \\
\hline \multirow[t]{2}{*}{ August } & Flu-like & 1.79 & $1.23-2.59$ & 0.002 \\
\hline & Others & 1.20 & $0.60-2.40$ & 0.616 \\
\hline COVID-19 Diagnosis & No & Ref & ----- & ----- \\
\hline since August & Yes & 3.57 & 2.27-5.63 & $<0.001$ \\
\hline
\end{tabular}

${ }^{1}$ Variables obtained at 1 st Cohort Visit except when indicated.

* Incidence Rate Ratio (IRR) using Poisson Regression considering follow-up time with robust variance corrected by clusters, and adjusted per all model variables. 


\section{Figures}

A

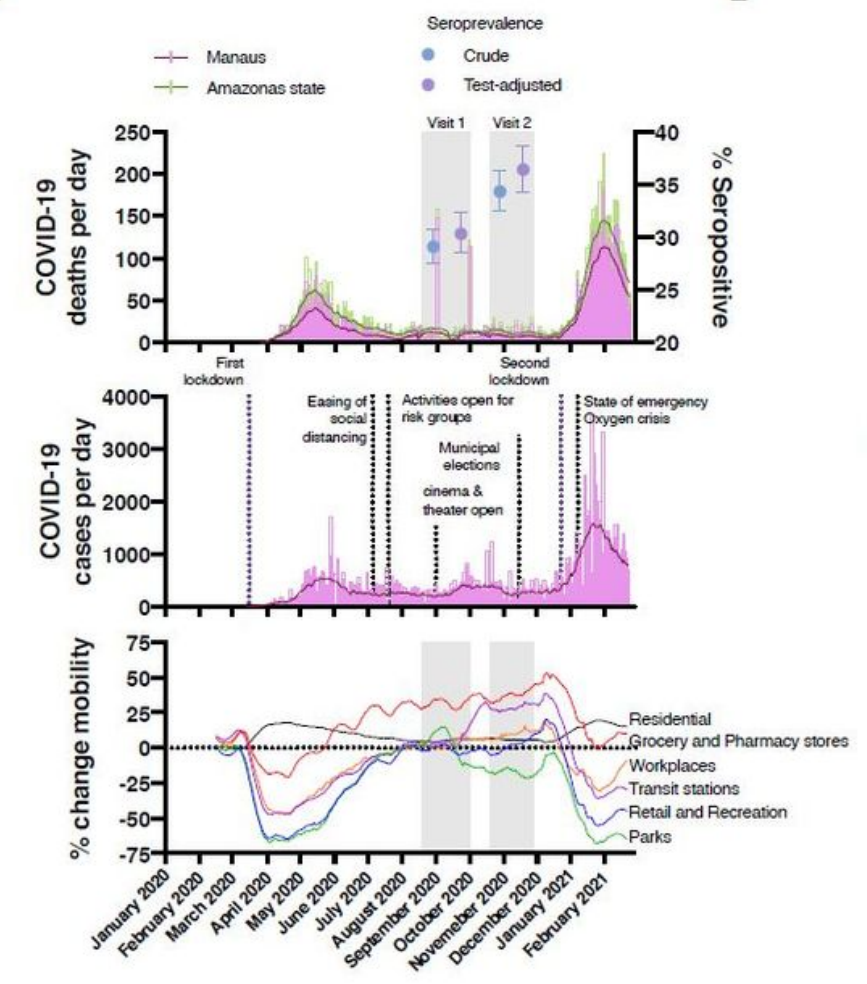

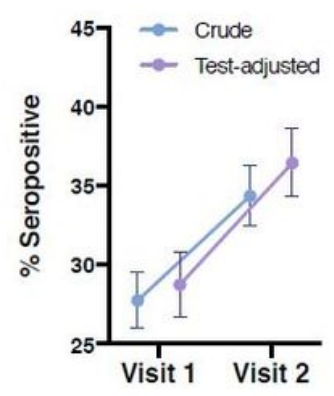

D

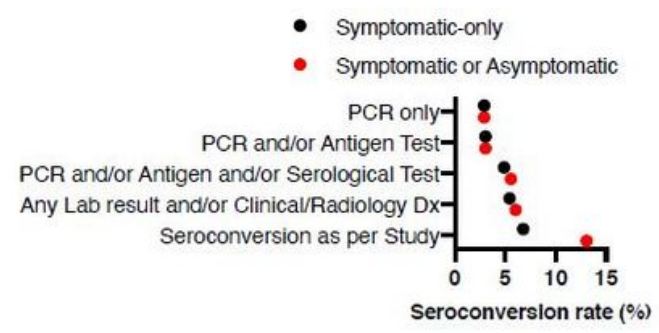

C

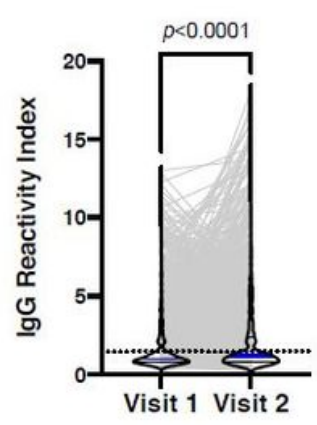

$\mathrm{E}$

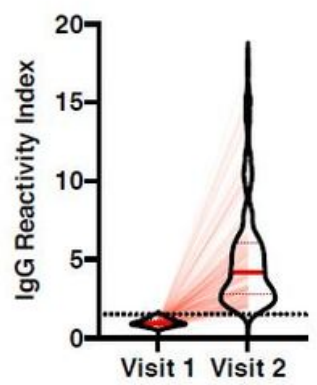

Figure 1

Anti-SARS-COV-2 nucleocapsid antibody prevalence and seroconversion before the second wave of infection from the DETECTCoV-19 cohort in Manaus. (a) COVID-19 confirmed deaths (upper plot) and cases (middle plot), obtained from the Fundação de Vigilância em Saúde do Amazonas

(http://www.fvs.am.gov.br, date accessed 28 February, 2021). Events following the SARS-CoV-2 pandemic were collated from the Amazonas state government website (http://www.amazonas.am.gov.br, date accessed 28 February, 2021); NPI-related, public health measures, and pandemic-related events depicted (text inserts, middle plot). Publicly available Google mobility data for Manaus city was obtained (https://www.google.com/covid19/mobility/, date accessed 01 March 2021) and plotted as percentage mobility change (lower plot). Crude and test-adjusted anti-SARS-COV-2 nucleocapsid antibody seropositivity prevalence depicted as percentage of seropositive individuals for both study visits (whole cohort seroprevalence, upper plot; bars depict $95 \% \mathrm{Cl}$ ). (b) Seroprevalence in individuals that returned to second visit $(n=2,496$; bars depict $95 \% \mathrm{Cl})$. (c) IgG Reactivity Index (RI) of paired samples from 1 st and 2nd visits. Blue horizontal line denotes median values. Paired samples depicted by grey lines. (d) Seroconversion rates according to case definitions for symptomatic and asymptomatic (red) or asymptomatic-only individuals (black). (e) Paired RI of individuals who seroconverted as per study protocol. Red horizontal line denoted the median values in the violin plots. Dotted line at RI 1.5 denotes assay cut-off. Bars depict $95 \% \mathrm{Cl}$, dotted lines ( $c$ and d) depict IR cutoff $(\mathrm{IR}=1.5)$. 


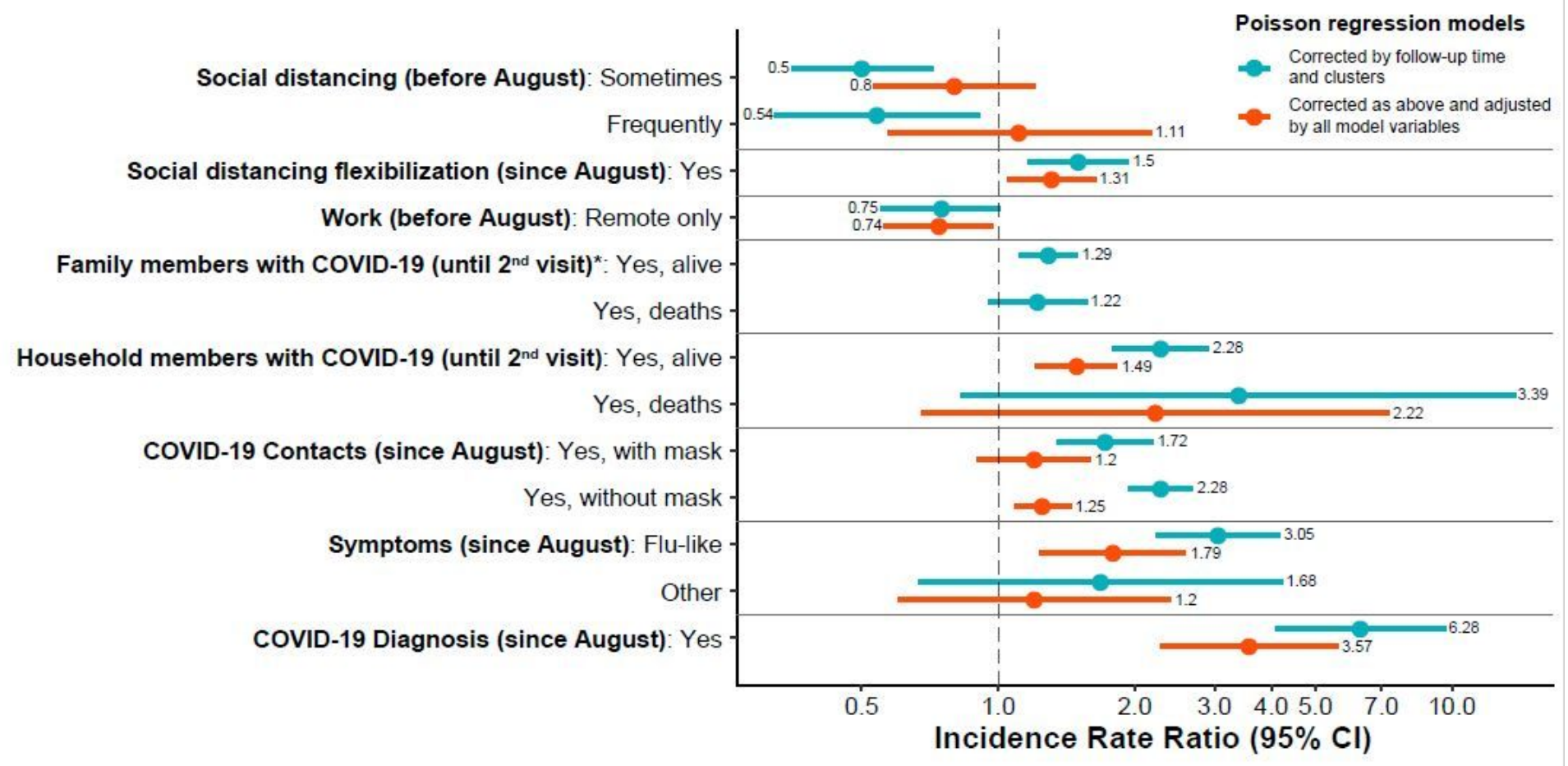

\section{Figure 2}

Multivariate regression model for SARS-CoV-2 seroconversion in a general population cohort from Manaus, Amazonas state of Brazil (N=1,618). Forest Plot showing Incidence Rate Ratios (IRR) obtained via Poisson Regression considering follow-up time with robust variance corrected by clusters. IRRs are shown unadjusted and adjusted per all model variables (please refer Supplementary Table 5 for details). *Not included in the multivariate model due to collinearity with the Household contact variable. 